\title{
A study of cutaneous adverse drug reaction patterns with causality and severity assessment at a tertiary care centre
}

\author{
Dhaval B Joshi ${ }^{1}$, Rashmi Mahajan ${ }^{2, *}$, Kishan Ninama ${ }^{3}$, Foram Shukla ${ }^{4}$, Charansakhi Panchal ${ }^{5}$ \\ ${ }^{\mathbf{1}}$ Assistant Professor, ${ }^{\mathbf{2}, \mathbf{3}}$ Associate Professor, ${ }^{\mathbf{4}, 5}$ Pharm D Student, ${ }^{\mathbf{2}, 3}$ Dept. of Skin \& VD, ${ }^{\mathbf{1 , 4}, \mathbf{5}}$ Dept. of Pharmacy, S.B.K.S. Medical \\ Institute \& Research Centre Sumandeep Vidyapeeth University, Gujarat, India
}

*Corresponding Author:

Email: rsoodmahajan@gmail.com

\begin{abstract}
Introduction: Prescribed medications are intended to relieve sufferings during the course of illness. Occasionally due to the unpredictable pharmacological nature of the drug, the unique physiological condition of the patients and/or due to any other factors, drugs cause Adverse Drug Reactions (ADRs). Few of the ADRs are quite severe and if not adequately and promptly managed, may lead to serious complications and even death. Apart from this, the high frequency of obnoxious ADRs may also drive the patients to question the reliability of the given pharmacotherapy and that may further lead to medication nonadherance. Cutaneous ADRs are quite common and few of them are very severe which lead to significant comorbidities. Early identification of the condition as well as the culprit drug and omitting it at earliest holds the keystone in management and prevention of a more serious reaction. Thus, it is necessary to have a sound monitoring and reporting of cutaneous ADRs and also an adequate analysis and interpretation of their entire pattern of the occurrence.

Aim: To study the patterns of cutaneous adverse drug reactions with causality and severity assessment in tertiary care hospital.

Objective: To Identify, analyse and report cutaneous ADRs and drug classes responsible for the same.

Materials and Methods: A Prospective study was carried out over a period of 5 months among the out-patients and in-patients in Department of Skin and Venereal Diseases. A total of 35 patients were enrolled as per selection criteria. Chi-square test was applied in order to investigate whether the distribution of categorical variables differ from one another.

Result: Out of 35 patients enrolled in the study, 12 patients had maculopapular drug rash and the commonest causative drug was phenytoin. 9 patients in the study had fixed drug reaction, the commonest cause was nimesulide. 4 patients were of erythema multiforme, the commonest cause was NSAIDS. 3 patients each of Toxic Epidermal Necrolysis and Steven Johnson syndrome. There was 1 case of idiosyncratic drug toxicity due to methotrexate, 1 case of Drug Reaction with Eosinophilia and Systemic Symptoms due to phenytoin, 1 case of drug induced urticaria due to metronidazole and 1 case of bullous drug reaction.

Conclusion: After the cutaneous drug eruption was diagnosed and treated, Patients were counselled and provided with the ADR alert card provided for emergency condition.
\end{abstract}

Keywords: Adverse drug reactions, Cutaneous, Naranjo, Hartwig.

\section{Introduction}

The World Health Organisation (WHO) defines an ADR as "a response to a drug which is noxious and unintended, and which occurs at doses normally used in man for the prophylaxis, diagnosis, or therapy of disease, or for the modification of physiological function."1

ADRs causes alterations in functions of various organ systems such as respiratory system, vascular system, nervous system, musculoskeletal system, urinary system, skin and appendages, biliary system and gastrointestinal system. ${ }^{2}$

In our hospital settings we have observed some notably harmful and detrimental cutaneous reactions. The main motive of this study was to ascertain the specific site, type of cutaneous ADR, causative drug and drug class along with any risk factors.

Cutaneous ADR caused by a drug is any undesirable change in the structure or function of the skin, its appendages or mucous membranes and it encompasses all adverse events related to drug eruption, regardless of the etiology.

The most common cutaneous manifestations are maculopapular rash, morbilliform drug eruption, Fixed
Drug Eruption (FDE), Erythema Multiforme (EM), Stevens-Johnson syndrome (SJS), Toxic Epidermal Necrolysis (TEN), Drug Reaction with Eosinophilia and Systemic Symptoms (DRESS), Drug Hypersensitivity syndrome (DHS), lichenoid drug eruption, photoallergic drug eruption, urticarial, and drug induced vasculitis. ${ }^{2}$

The most predominating drug classes responsible for causing cutaneous conditions are antibiotics, antimicrobials, NSAIDS, sulfa drugs, biopharmaceuticals, chemotherapy agents, anticonvulsants and psychotrophic drugs. On the contrary, there are certain drugs which are less likely to cause cutaneous drug eruptions including digoxin, aluminum hydroxide, multivitamins, acetaminophen, bisacodyl, aspirin, thiamine, prednisone, atropine, codeine, hydrochlorothiazide, morphine, insulin, warfarin, and spironolactone. ${ }^{2}$

Cutaneous ADRs are frequent and affects 2-3\% of all hospitalized patients. It is found that approximately $2 \%$ of cutaneous ADRs are severe whereas most of the other drug eruptions are mild and self-limiting. The incidence of cutaneous ADRs in developed countries range from $1-3 \%$ among the in-patients, whereas in 
developing countries such as India, some studies show that it is $2-5 \%$ of the in-patients. This difference is observed due to varying prescribing habits and level of health care. However, the assimilation of offending drug enables early withdrawal and improved outcomes. Furthermore, it is established from most studies that the symptoms of reactions alleviate after the offending drug has been discontinued. ${ }^{3}$

\section{Materials and Methods}

Before initiating the study, publications describing cutaneous ADRs in Indian population were thoroughly searched using electronic databases such as Google Scholar, PubMed, Micromedex, Medscape, and Medline. The bibliographies of relevant articles were also taken into account and the considerable points from suitable articles were discussed with guide and clinical guide.

Furthermore, a systematic procedure of performing the study was devised and an appropriate title for the study was framed. The sample size was calculated with the assistance of statistician and thereafter the first stone of our study was laid by initiating data collection process.

The data collection for this prospective observational study was carried out with intensive monitoring for a period of 6 months in Dermatology Department. First, written informed consent of the subjects were taken via Informed Consent Form (ICF).
Patients with the presence of clinical features suggestive of cutaneous ADRs pertaining to allopathic medications were clinically observed and included in our study. In contrast to this, the patients on nonallopathic medications such as homeopathic, ayurvedic and herbal were excluded from the study.

Patient's demographics (age, gender, body weight), history of present illness (duration, causative drug, type of reaction, constitutional symptoms), general physical examination, cutaneous examination and relevant lab reports were analysed. On the basis of patient's medication history, clinical presentation and lab data; the diagnosis regarding cutaneous ADR was carried out. The photographs of clinical features suggesting drug related cutaneous reactions were also captured. Biopsy was performed when required. Suspected ADR was monitored on the basis of regular follow ups carried out by the clinicians and the relevant data of clinical features obtained by each follow up was documented by the researchers.

Causality of the ADR was measured with the help of Naranjo's Algorithm and severity of ADR was measured by Hartwig and Siegel scale (Fig. 1 \& Table 1). An ADR alert card was issued to the patient to notify other clinicians about the suspected drug and to refrain them from prescribing it (Fig. 2). Patient Education Leaflet was also provided to patient for better understanding of cutaneous ADR and their prevention. Finally, statistical tests such as Chi-square test and p-value were applied and results were drawn.

\begin{tabular}{|c|c|c|c|c|}
\hline \multicolumn{5}{|l|}{ Adverse Drug Reaction Probability Scale } \\
\hline Question & Yes & No & $\begin{array}{c}\text { Do Not } \\
\text { Know }\end{array}$ & Score \\
\hline 1. Are there previous conclusive reports on this reaction? & +1 & 0 & 0 & \\
\hline $\begin{array}{l}\text { 2. Did the adverse event appear after the suspected drug was } \\
\text { administered? }\end{array}$ & +2 & -1 & 0 & \\
\hline $\begin{array}{l}\text { 3. Did the adverse event improve when the drug was discontinued or a } \\
\text { specific antagonist was administered? }\end{array}$ & +1 & 0 & 0 & \\
\hline 4. Did the adverse event reappear when the drug was readministered? & +2 & -1 & 0 & \\
\hline $\begin{array}{l}\text { 5. Are there alternative causes that could on their own have caused the } \\
\text { reaction? }\end{array}$ & -1 & +2 & 0 & \\
\hline 6. Did the reaction reappear when a placebo was given? & -1 & +1 & 0 & \\
\hline $\begin{array}{l}\text { 7. Was the drug detected in blood or other fluids in concentrations } \\
\text { known to be toxic? }\end{array}$ & +1 & 0 & 0 & \\
\hline $\begin{array}{l}\text { 8. Was the reaction more severe when the dose was increased or less } \\
\text { severe when the dose was decreased? }\end{array}$ & +1 & 0 & 0 & \\
\hline $\begin{array}{l}\text { 9. Did the patient have a similar reaction to the same or similar drugs in } \\
\text { any previous exposure? }\end{array}$ & +1 & 0 & 0 & \\
\hline \multirow[t]{2}{*}{ 10. Was the adverse event confirmed by any objective evidence? } & +1 & 0 & 0 & \\
\hline & \multicolumn{4}{|c|}{ Total Score: } \\
\hline
\end{tabular}




\begin{tabular}{||c|l||}
\hline \hline \multicolumn{1}{|c||}{ Naranjo Algorithm - ADR Probability Scale } \\
\hline Score & Interpretation of Scores \\
\hline $\begin{array}{c}\text { Total } \\
\text { Score } \\
\geq 9\end{array}$ & $\begin{array}{l}\text { Definite. The reaction (1) followed a reasonable temporal sequence after a drug or in } \\
\text { which a toxic drug level had been established in body fluids or tissues, (2) followed a } \\
\text { recognized response to the suspected drug, and (3) was confirmed by improvement on } \\
\text { withdrawing the drug and reappeared on reexposure. }\end{array}$ \\
\hline $\begin{array}{c}\text { Total } \\
\text { Score } \\
5 \text { to } 8\end{array}$ & $\begin{array}{l}\text { Probable. The reaction (1) followed a reasonable temporal sequence after a drug, (2) } \\
\text { followed a recognized response to the suspected drug, (3) was confirmed by withdrawal } \\
\text { but not by exposure to the drug, and (4) could not be reasonably explained by the } \\
\text { known characteristics of the patient's clinical state. }\end{array}$ \\
\hline $\begin{array}{c}\text { Total } \\
\text { Score } \\
1 \text { to } 4\end{array}$ & $\begin{array}{l}\text { Possible. The reaction (1) followed a temporal sequence after a drug, (2) possibly } \\
\text { followed a recognized pattern to the suspected drug, and (3) could be explained by } \\
\text { characteristics of the patient's disease. }\end{array}$ \\
\hline $\begin{array}{c}\text { Total } \\
\text { Score } \\
\leq 0\end{array}$ & \begin{tabular}{l} 
Doubtful. The reaction was likely related to factors other than a drug. \\
\hline
\end{tabular} \\
\hline
\end{tabular}

Fig. 1: Naranjo probability

Table 1: Hartwig \& Siegel scale

\begin{tabular}{|l|l|}
\hline Severity Level & \multicolumn{1}{c|}{ Description } \\
\hline 1. & An ADR occurred but no change in treatment with suspected drug. \\
\hline 2. & $\begin{array}{l}\text { The ADR required treatment with suspected drug withheld, discontinued/changed. } \\
\text { No antidote/other treatment required. } \\
\text { No increased length of hospital stay. }\end{array}$ \\
\hline 3. & $\begin{array}{l}\text { ADR required treatment with suspected drug withheld, discontinued/changed and required } \\
\text { an antidote or other treatment. } \\
\text { No increased length of hospital stay. }\end{array}$ \\
\hline 4. & $\begin{array}{l}\text { Any level 3 ADR which increased length of stay at least by 1 day/the ADR was reason for } \\
\text { administration }\end{array}$ \\
\hline 5. & Any level 4 ADR which required intensive medical care \\
\hline 6. & ADR caused permanent harm to the patient \\
\hline $7 \mathrm{a}$ & ADR was indirectly linked to death of the patient \\
\hline $7 \mathrm{~b}$ & ADR was directly linked to death of the patient \\
\hline Mild & Level 1 and 2 \\
\hline Moderate & Level 3 and 4 \\
\hline Severe & Level 5, 6 and 7 \\
\hline
\end{tabular}
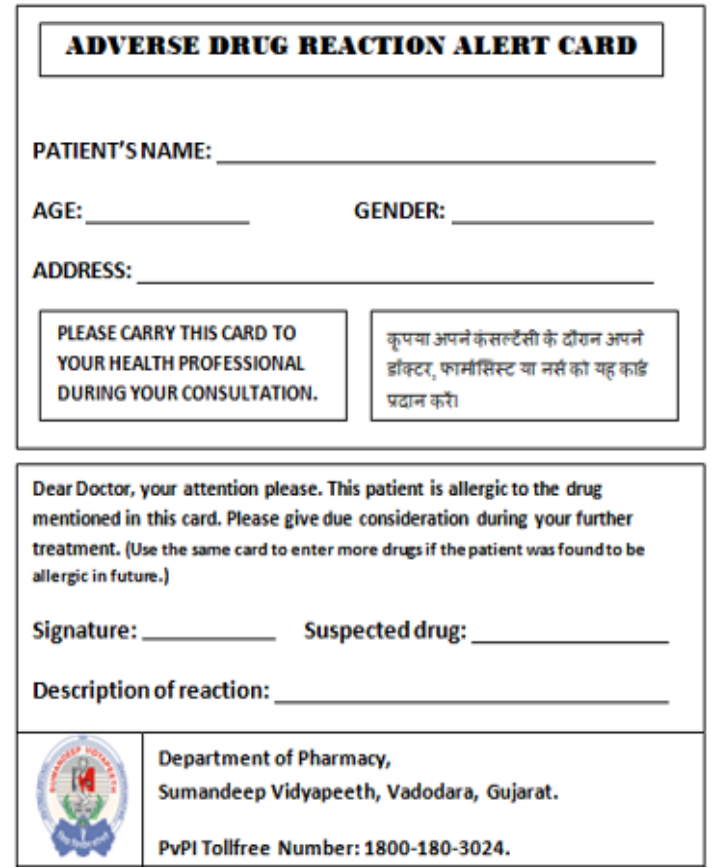

Fig. 2: Adverse drug reaction alert card 


\section{Results}

All together 35 patients suggestive of cutaneous drug reaction were included in our study. An elaborated analysis of all the findings are given below.

Patient demographics

Amidst 35 patients, 19 (54\%) were males and 16 $(46 \%)$ were female.

In our study, the age of the patients ranged from 14 years to 70 years, additionally, the mean age of male and female patients was $35.26 \pm 15.13$ years and 35.26 \pm 15.13 years respectively. [Table 2]

Table 2: Age

\begin{tabular}{|l|c|c|}
\hline \multicolumn{1}{|c|}{ Gender } & Number of patients & Percentage \\
\hline Male & 19 & $54 \%$ \\
\hline Female & 16 & $46 \%$ \\
\hline Total & 35 & $100 \%$ \\
\hline & & \\
\hline Gender & Mean & STDEV \\
\hline Male & 35.26 & 15.13 \\
\hline Female & 35.26 & 15.13 \\
\hline
\end{tabular}

The maximum number of cutaneous ADRs were observed in the age group of 21-30 years $(\mathrm{N}=11)$ followed by the age group of 31-40 years $(\mathrm{N}=8), 11-20$ years $(\mathrm{N}=5), 41-50$ years $(\mathrm{N}=5), 51-60$ years $(\mathrm{N}=4)$ respectively. In contrast to this, the least number of cutaneous ADRs were found in senior age group of 6170 years $(\mathrm{N}=2)$.

\section{Diagnosis of Cutaneous ADRs}

During the course of cutaneous examination of outpatients and in-patients in the skin OPD various manifestations of cutaneous ADR were detected.

The paramount reaction that highlighted amidst all types of cutaneous ADRs was maculopapular rash (Fig. 3). Total 12 patients have developed maculopapular rash. [Table 3]
Table 3: Diagnosis

\begin{tabular}{|l|c|c|}
\hline \multicolumn{1}{|c|}{ Diagnosis } & Total & \% \\
\hline Dress & 1 & $2.86 \%$ \\
\hline Fixed drug reaction & 9 & $25.71 \%$ \\
\hline Erythema multiforme & 4 & $11.43 \%$ \\
\hline Maculopapular rash & 12 & $34.29 \%$ \\
\hline $\begin{array}{l}\text { Methotrexate induced } \\
\text { reaction }\end{array}$ & 1 & $2.86 \%$ \\
\hline Idiopathic drug toxicity & 1 & $2.86 \%$ \\
\hline $\begin{array}{l}\text { Steven jhonson's } \\
\text { syndrome }\end{array}$ & 3 & $8.57 \%$ \\
\hline $\begin{array}{l}\text { Toxic epidermal } \\
\text { necrolysis }\end{array}$ & 3 & $8.57 \%$ \\
\hline Urticaria & 1 & $2.86 \%$ \\
\hline Total & $\mathbf{3 5}$ & $\mathbf{1 0 0 . 0 0 \%}$ \\
\hline
\end{tabular}

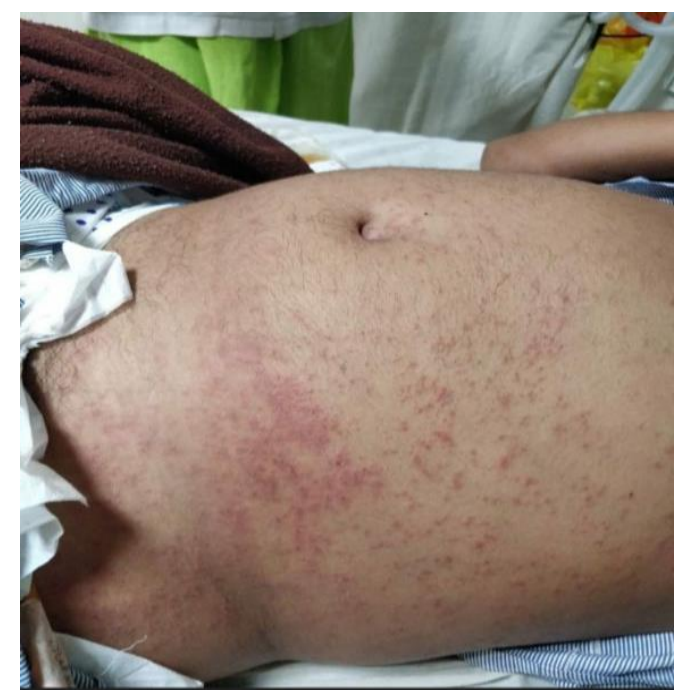

Fig 3: Nimesulide induced erythematous maculopapular rash on trunk and limbs

The second most common cutaneous ADR identified was FDE (Fig. 4), affecting total 9 patients. Chronologically, other reactions accounted were EM with total 4 patients, SJS and TEN (Fig. 5a, b) each were seen in total 3 patients.

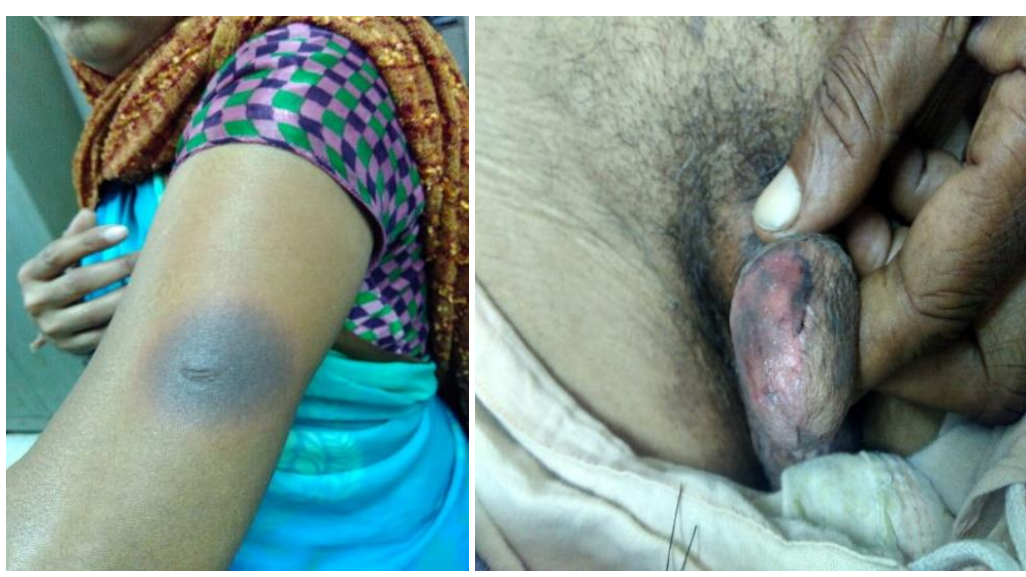

Fig 4: Ofloxacin induced fixed drug eruption on hand and glans penis 
Furthermore, other cutaneous ADRs identified were DRESS, bullous drug eruption, idiosyncratic drug reaction and drug induced urticaria.

\section{Causative Drugs for Cutaneous ADRs}

Among the various drugs attributed for the causation of cutaneous ADR in the study population, phenytoin and nimesulide were noted to be the most involved drug for causing cutaneous ADR each with 8 cases.

Furthermore, occurrence of reaction from olfoxacin, carbamazepine, co-trimoxazole, cefpodoxine, furazolidone and tramadol each were witnessed in 2 patients. (Table 4 )
Table 4: Causative Drug

\begin{tabular}{|l|c|c|}
\hline $\begin{array}{c}\text { Most common causative } \\
\text { drug }\end{array}$ & Total & $\mathbf{\%}$ \\
\hline Carbamazepine & 2 & $5.71 \%$ \\
\hline Cefpodoxime & 2 & $5.71 \%$ \\
\hline Combination & 3 & $8.57 \%$ \\
\hline Co-trimoxazole & 2 & $5.71 \%$ \\
\hline Furazolidone & 2 & $5.71 \%$ \\
\hline Methotrexate & 1 & $2.86 \%$ \\
\hline Metronidazole & 1 & $2.86 \%$ \\
\hline Nimesulide & 8 & $22.86 \%$ \\
\hline Ofloxacin & 2 & $5.71 \%$ \\
\hline Amoxicillin & 1 & $2.86 \%$ \\
\hline Phenytoin & 8 & $22.86 \%$ \\
\hline Tramadol & 2 & $5.71 \%$ \\
\hline Unknown & 1 & $2.86 \%$ \\
\hline Total & $\mathbf{3 5}$ & $\mathbf{1 0 0 . 0 0 \%}$ \\
\hline
\end{tabular}
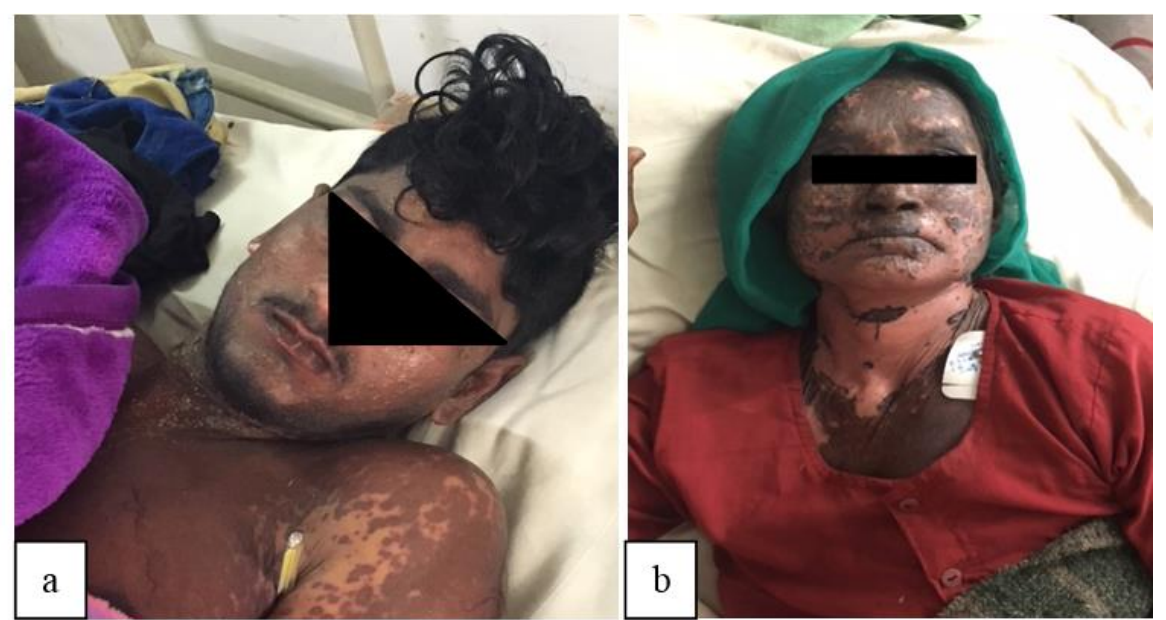

Fig 5a: Carbamazepine-induced Steven Johnson syndrome and toxic epidermal necrolysis]; (b): Ofloxacininduced toxic epidermal necrolysis]

Other drugs liable for causality of cutaneous ADRs includes metronidazole, methotrexate and amoxicillin each reporting single case. Idiosyncratic drug toxicity was seen in 1 patient. Tablet containing combination of cetrizine, acetaminophen and phenylephrine was consumed by 1 patient having cutaneous ADR. Moreover, 1 patient was on medications such as roxithromycin, levocetrizine and combined tablet of dextromethorphan, phenylephrine, cpm etc.
Cutaneous Examination: The patients enrolled in the study were examined thoroughly to determine the pattern of cutaneous reaction including site specific involvement. The table below is composite, selfexplanatory and numerically depicts the incidence of site of reaction in the subject. The cutaneous examination of patients who ingested causative drugs showed reaction on various body parts as show in [Table $5 \& 6$ ).

Table 5: Site of reaction

\begin{tabular}{|l|c|c|c|c|c|c|c|c|c|}
\hline Drug & $\begin{array}{c}\text { Cutaneous } \\
\text { Involvement } \\
\text { Head, neck } \\
\text { Face }\end{array}$ & Scalp & Trunk & Back & $\begin{array}{c}\text { Palms } \\
\text { Soles }\end{array}$ & Oral & Genitals & Limb & Eyes \\
\hline Carbamazepine & 2 & 0 & 2 & 2 & 1 & 2 & 1 & 2 & 2 \\
\hline Amoxicillin & 0 & 0 & 0 & 0 & 1 & 0 & 0 & 0 & 0 \\
\hline Cefpodoxime & 0 & 0 & 2 & 1 & 2 & 0 & 0 & 0 & 0 \\
\hline $\begin{array}{l}\text { Combination } \\
\text { drugs }\end{array}$ & 2 & 1 & 2 & 1 & 2 & 2 & 1 & 1 & 1 \\
\hline
\end{tabular}




\begin{tabular}{|l|l|l|l|l|l|l|l|l|l|}
\hline Co-trimoxazole & 0 & 0 & 0 & 0 & 2 & 2 & 2 & 0 & 0 \\
\hline Furazolidone & 1 & 0 & 0 & 0 & 0 & 1 & 2 & 0 & 0 \\
\hline Methotrexate & 0 & 1 & 1 & 0 & 0 & 1 & 1 & 0 & 0 \\
\hline Metronidazole & 0 & 0 & 1 & 0 & 0 & 0 & 0 & 0 & 0 \\
\hline Nimesulide & 4 & 1 & 2 & 3 & 1 & 6 & 4 & 0 & 1 \\
\hline Ofloxacin & 1 & 0 & 1 & 0 & 0 & 1 & 2 & 1 & 1 \\
\hline Phenytoin & 6 & 1 & 3 & 3 & 1 & 3 & 1 & 5 & 1 \\
\hline Idiopathic drug & 0 & 0 & 1 & 0 & 0 & 1 & 0 & 0 & 0 \\
\hline Tramadol & 0 & 0 & 2 & 1 & 2 & 0 & 0 & 1 & 0 \\
\hline
\end{tabular}

Table 6: Cutaneous reaction caused by different drugs

\begin{tabular}{|l|c|c|}
\hline Drug & Type of reaction & Number of patients \\
\hline Phenytoin & Maculopapular rash & 5 \\
\hline & Steven johnson syndrome & 1 \\
\hline & Dress & 1 \\
\hline Carbamazepine & Bullous drug eruption & 1 \\
\hline & Maculopapular rash & 1 \\
\hline Nimesulide & Toxic epidermal necrolysis & 2 \\
\hline & Maculopapular rash & 5 \\
\hline & Fixed drug eruption & 1 \\
\hline Tramadol & Erythema multiforme & 2 \\
\hline Ofloxacin & Maculopapular rash & 1 \\
\hline & Toxic epidermal necrolysis & 1 \\
\hline Cefpodoxime & Fixed drug eruption & 2 \\
\hline Co-trimoxazole & Maculopapular rash & 2 \\
\hline Furazolidone & Fixed drug eruption & 1 \\
\hline & Fixed drug eruption & 1 \\
\hline Amoxicillin & Steven johnson syndrome & 1 \\
\hline Metronidazole & Erythema multiforme & 1 \\
\hline Methotrexate & Urticaria & 1 \\
\hline Combination drugs & Methotrexate induced reaction & 1 \\
\hline & Steven johnson syndrome & 1 \\
\hline & Toxic epidermal necrolysis & 1 \\
\hline Idiopathic drug & Erythema multiforme & 1 \\
\hline & Erythema multiforme & \\
\hline & & \\
\hline & & \\
\hline & & \\
\hline & & \\
\hline & & \\
\hline
\end{tabular}

While examining the patients with various cutaneous ADRs, anticonvulsants were found as the most common class cumulating 10 cases out of 35 . This class demonstrated higher significance when compared to other classes $\left(p=0.0001, x^{2}=33.90\right)$. NSAIDs subordinated with the report of 8 cases. Therefore, it is important to know that similar drugs can cause different reactions. For instance, in the present study anticonvulsants have caused maculopapular rash, SJS, TEN, bullous drug eruption and DRESS (Fig. 6). Similarly, NSAIDs were reported in maculopapular rash, fixed drug eruption and EM. 


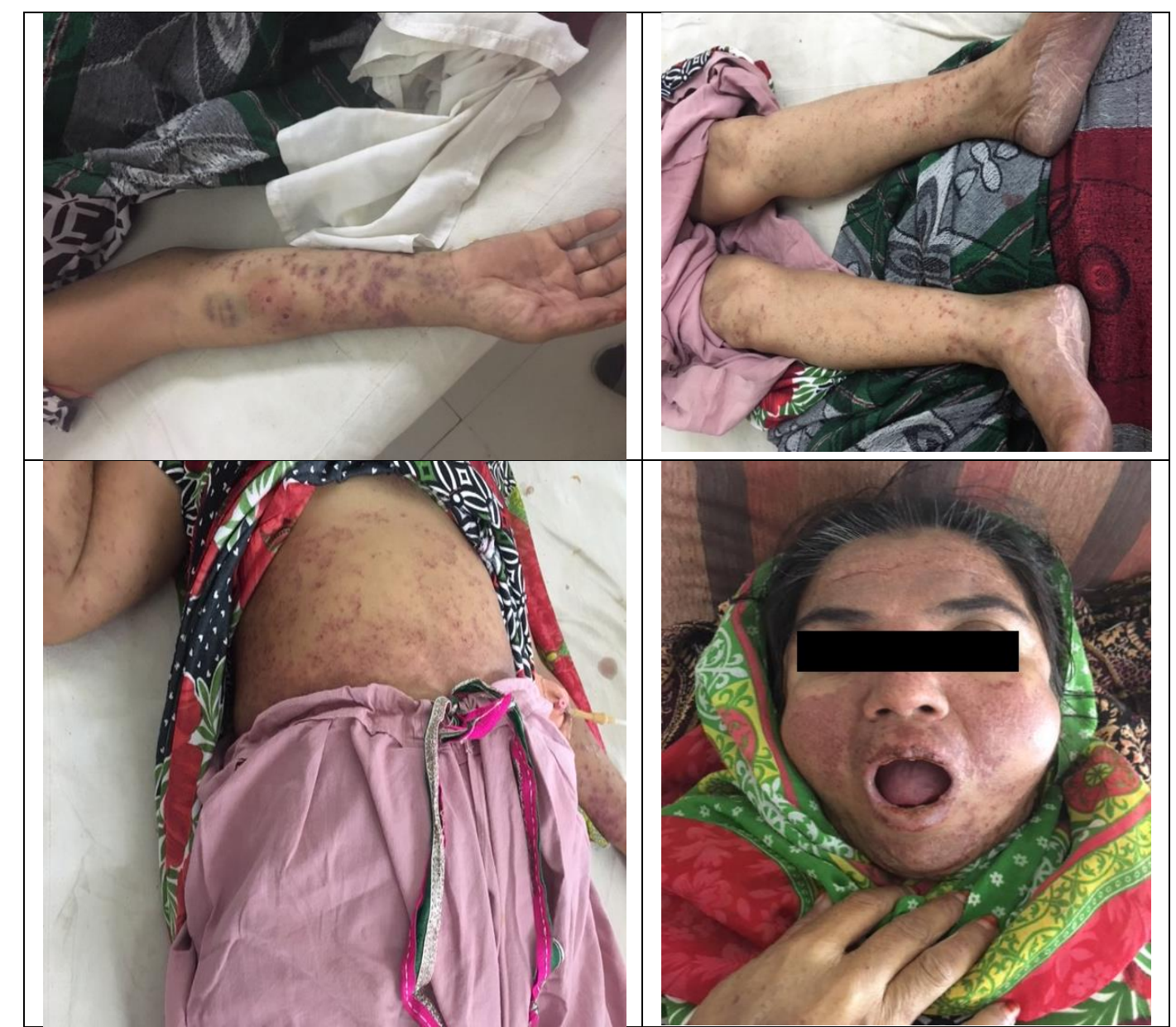

Fig 6: Phenytoin induced drug reaction with eosinophilia and systemic symptoms

Other drug classes involved for causing cutaneous ADRs were fluoroquinolones, antibiotics, cephalosporins, analgesics, antimetabolites, antimicrobials and opioid analgesics as shown in the [Table 7).

Table 7: Most common drug class

\begin{tabular}{|l|c|c|}
\hline \multicolumn{1}{|c|}{ Drug class } & Total & \% \\
\hline Anticonvulsants & 10 & $29 \%$ \\
\hline Nsaids & 8 & $23 \%$ \\
\hline Flouroquinolones & 2 & $6 \%$ \\
\hline Penicillins & 1 & $3 \%$ \\
\hline Nitroimidazoles & 1 & $3 \%$ \\
\hline Cephalosporins & 2 & $6 \%$ \\
\hline Sulfonamides & 2 & $6 \%$ \\
\hline Antimetabolites & 1 & $3 \%$ \\
\hline Nitrofurantoins & 2 & $6 \%$ \\
\hline Opioid analgesics & 2 & $6 \%$ \\
\hline Unknown & 1 & $3 \%$ \\
\hline Combinations & 3 & $9 \%$ \\
\hline Total & 35 & $100 \%$ \\
\hline
\end{tabular}

Causality and Severity Assessment: As per Naranjo's severity scale criteria, $93 \%$ of cutaneous ADRs were found to be probable and the rest $(6 \%)$ were found to be possible

Assessment done as per Hartwig scale showed that $83 \%$ of cutaneous ADRs were categorised as moderate and $17 \%$ constituted severe category.

\section{Discussion}

Gender Ratio: Out of 35 patients in our study, 19 were males and 16 were females. Therefore, male to female ratio established was 1.17:1 which is suggestive of slight predominance of male population. In contrast to this, we have come across two academic work done by Abanti Saha et $\mathrm{al}^{4}$ and Padukadan et al which have shown that male to female ratio was found to be $0.96: 1$ and $0.87: 1$ respectively.

Age: In our study, age of patients was ranging from 14 years to 70 years. Furthermore, it is seen that $68.57 \%$ of subjects were having the age less than 40 years. This result is quite consistent with the result obtained in another study carried out by Tejas $\mathrm{K}$ Patel et $\mathrm{al}^{5}$ in which the majority of population (70\%) was having age less than 40 years.

A slight deviating from the present study, we have encountered a study conducted by Raksha Marfatia et 
$\mathrm{al}^{6}$ in which majority of patients belonged to the age group of 41-50 years.

In a nutshell, we may conclude that most of the patients who developed cutaneous ADRs were young and adult population rather than geriatrics.

Types of Cutaneous ADRs: The most common clinical pattern of drug reaction in the current study was found to be maculopapular rash which is similar to the study conducted by Tejas $\mathrm{K}$ Patel et $\mathrm{al}^{5}$ which also highlighted maculopapular rash as the most common cutaneous ADR with total incidence of $32.32 \%$. Other than this, research study conducted by Mahmood Farschian et $\mathrm{al}^{7}$ pinpointed acute urticaria as the most common cutaneous ADR with total incidence of $52.9 \%$. Common Causative Drugs: One of the different outcomes we have obtained in our exploration compared to other relevant findings was the identification of phenytoin and nimesulide as the most commonly involved drugs causing cutaneous ADRs. The highest frequency of cutaneous ADRs we have obtained is with phenytoin and nimesulide. On the other hand, the investigation conducted by Hotchandani S C et $\mathrm{al}^{8}$, Rohini Sharma et $\mathrm{al}^{9}{ }^{9}$ Tejas K Patel et $\mathrm{al}^{5}$ and Mahmood Farshchian et $\mathrm{al}^{7}$ has shown antimicrobials to be the most common causative agents.

In contrast, the few other studies conducted by authors Raksha Marfatia et al, ${ }^{7}$ Surjit Nayak et $\mathrm{al}^{3}$ and Abanti Saha et $\mathrm{al}^{4}$ depicts that the maximum number of cutaneous ADRs were due to causative drugs cotrimoxazole, carbamazepine and sulfonamides respectively.

Causality Assessment: Results drawn as per Naranjo's severity scale criteria demonstrates that $93 \%$ of cutaneous ADRs were evaluated as being probable and $6 \%$ constituted the possible category.

The results of present study is contradictory to the study performed by Rohini Sharma et al, ${ }^{9}$ in which Naranjo ADR probability scale indicated probable association of $77.3 \%$, highly probable association of $12.6 \%$, and $1 \%$ possible association with the implicated drugs.

Reasons behind lesser score on Naranjo probability scale in our study:

1. The suspected drugs were not re-administered.

2. Lack of relevant lab data.

3. There was no objective evidence available.

Severity Assessment: Assessment done as per Hartwig scale in our present study showed that $83 \%$ of cutaneous ADRs were assigned as moderate and $17 \%$ were placed in severe category. The lesser percentage of severe reactions in our study is attributed to the proper management of cutaneous ADRs.

Clinical inspection by D.Acharya ${ }^{10}$ et al has identified that the highest category of cutaneous ADRs in terms of severity assessment based on Hartwig scale was moderate $(52 \%)$. The next in line was severe category with $27 \%$. Least number of patients were placed in mild category (21\%).

Distinguished Feature of the Present Study: One of the distinguished outcome we have obtained in our appraisal is the description of the different sites involved in specific cutaneous ADR. We did a separate analysis for the involvement of the different sites in case of each drug related cutaneous ADRs. Cutaneous ADRs were observed on scalp, face, trunk, back, palms, soles, oral, genitals, head, neck, limbs and eyes depending on the pattern of cutaneous reactions seen.

\section{Conclusion}

The study that took place in the Department of Dermatology has drawn our attention towards several conclusions. Examining the data of gender ratio, it can be concluded that male patients have shown predominance over female patients in causing cutaneous ADRs.

The clinical spectrum of cutaneous ADRs reported from the Department of Dermatology has displayed a diversity of reactions. Maculopapular rash was found to be the most common among all other cutaneous ADRs. The second most common cutaneous ADR was FDE. Other reactions accounted were EM, SJS, TEN, DRESS, bullous drug eruption and urticaria. Some reactions have also prolonged the hospital stay of the patients. But, no fatalities due to cutaneous ADRs were reported.

The most common involved drugs causing cutaneous ADRs were phenytoin and nimesulide. Besides these agents, other drugs that seemed to participate in the trend of causing cutaneous ADRs were carbamazepine, co-trimoxazole, tramadol, cefpodoxine, furazolidone, methotrexate and metronidazole.

Among the drug classes responsible for causing cutaneous ADRs, anticonvulsants was found to be the most commonly involved drug class followed by NSAIDS. Other drug classes involved were fluoroquinolones, antibiotics, cephalosporins, analgesics, antimetabolites, antimicrobials and opioid analgesics

The majority of cutaneous ADRs were probable and a few were categorized as possible in causality assessment which was based on Naranjo scale. Besides this, the severity of reaction was decided on basis of the assessment results taken from Hartwig scale which disclosed that majority of reactions were moderately severe and a few reactions were also categorized as severe.

\section{Limitations}

Short duration of the study was one of the limitations as few of the results of our study were not consistent with those observed in studies conducted for longer duration. 
As we opted for just an observational study not an interventional, we have not carried out a rechallenge of a drug causing cutaneous ADR and this might have affected the causality assessment.

In some of the cases we could not obtain all the details regarding medication history (brand name, manufacturer, batch number and expiry date) and this has influenced documentation in our data collection procedure. This is due to the fact that several patients came from a rural background and did not have supportive data for the treatment they had already received.

\section{References}

1. Verma R, Vasudevan B, Pragasam V. Severe cutaneous adverse drug reactions. Medical Journal Armed Forces India. 2013;69(4):375-83.

2. Nayak S, Acharjya B. Adverse cutaneous drug reaction. Indian Journal of dermatology. 2008;53(1):2.

3. Das N, Hazra A, Gharami R, Chowdhury S, Datta P, Saha A. Cutaneous ADRs profile in a tertiary care outpatient setting in Eastern India. Indian Journal of Pharmacology. 2012;44(6):792.

4. Tejas. K. Patel. Cutaneous ADRs in Indian population: A systematic review: Indian Dermatology Journal. 2017;21(2)

5. Raksha MP, Marfatia YS. Clinical study of Cutaneous Drug Eruptions in 200 patients. Indian Journal of
Dermatolol Venereal Leprosy [serial online] 2008 [cited $29^{\text {th }}$ August 2017]; Available from: http.//www.ijdvl.com/text.asp?2008/74/1/180/38431.

6. Mahmood. $\mathrm{F}$ et al. Drug induced skin reactions: A 2 years study. Journal of Clinical, Cosmetic and Investigational Dermatology [serial online] 2015 [cited 2017 September $\left.11^{\text {th }}\right]$; 53:56. Available from https://www.dovepress.com/drug-induced-skin-reactionsa-2-years-study-peer-reviewed-article-CCID

7. Shah, M., Hotchandani, S. and Bhatt, J. (2010). A prospective analysis of drug-induced acute cutaneous reactions reported in patients at a tertiary care hospital. Indian Journal of Pharmacology. 2010;42(2):117.

8. Rohini Sharma et al. A study of cutaneous ADRs at a tertiary center in Jammu, India. Indian Dermatol Online J. 2015;6(3):168-171.

9. Acharya, L., Rao, P. and Ghosh, S. (2006). Study and evaluation of the various cutaneous adverse drug reactions in Kasturba hospital, Manipal. Indian Journal of Pharmaceutical Sciences. 2010;68(2):212.

How to cite this article: Joshi DB, Mahajan R, Ninama K, Shukla F, Panchal C. A study of cutaneous adverse drug reaction patterns with causality and severity assessment at a tertiary care centre. Ind J Clin Exp Dermatol. 2018;4(3):185193. 